\section{Trimethyl Orthoformate as a Highly Selective Mono-C-Methylating Agent for Arylacetonitriles}

\author{
Maurizio Selva*,† and Pietro Tundo
}

Dipartimento di Scienze Ambientali dell'U niversità Cà F oscari, Calle Larga S. Marta, 2137-31023 Venezia, I taly

Received May 12, 1998

The mono-C-methylation of arylacetonitriles $\left(\mathrm{ArCH}_{2-}\right.$ $\mathrm{CN}, \mathbf{1})$ to produce 2-aryl proprionitriles $\left[\mathrm{ArCH}\left(\mathrm{CH}_{3}\right) \mathrm{CN}\right.$, 2] represents a valuable reaction especially from a pharmaceutical standpoint. In fact, a number of compounds $\mathbf{2}$ are key intermediates for the synthesis of nonsteroidal analgesics of the hydratropic acid (2-arylpropanoic acid) class. ${ }^{1}$ Common well-known examples are I buprofen, Ketoprofen, and Naproxen (Chart 1).

However, synthetic procedures for the direct monomethylation of $\mathbf{1}$ fail with classical alkylating agents (methyl halides and dimethyl sulfate) because mixtures of mono- and dimethylated products are al ways obtained (Scheme 1). ${ }^{2}$ For instance, the alkylation of phenylacetonitrile with $\mathrm{CH}_{3} \mathrm{l}$ is reported with a mono- to dimethyl selectivity of $84 \%$, at a conversion of $86 \%{ }^{3}$

Although a number of multistep alkylation methods have been developed for the preparation of 2-arylpropanoic acids, ${ }^{1}$ the achievement of an effective one-pot procedure still represents a challenging task and may deserve attention from both the economical standpoint and the synthetic feasibility.

Concerning this, a very efficient procedure is the ruthenium-catalyzed reductive methylation of active methylene compounds carried out at $135-230^{\circ} \mathrm{C}$ with paraformaldehyde. ${ }^{4}$ However, we extensively reported that direct highly selective mono- $\mathrm{C}$-methylations of $\mathrm{CH}_{2}-$ acidic compounds $\left(\mathrm{YCH}_{2} \mathrm{X}\right)$ can also be performed by the use of dimethyl carbonate (DMC) as a methylating agent, without any metal catalyst..$^{5-11}$ Thus, at $180-210^{\circ} \mathrm{C}$ in the presence of weak bases $\left(\mathrm{K}_{2} \mathrm{CO}_{3}\right)$, aryl- and aroxyacetonitriles, methyl aryl- and aroxyacetates $(\mathrm{Y}=\mathrm{Ar}$, ArO; $\left.\mathrm{X}=\mathrm{CN}, \mathrm{CO}_{2} \mathrm{CH}_{3}\right)$, and $\alpha$-methylene sulfones $(\mathrm{Y}=$ $\mathrm{Ar}, \mathrm{X}=\mathrm{SO}_{2} \mathrm{Ar}, \mathrm{SO}_{2} \mathrm{R}$ ) yield the corresponding mono-Cmethyl derivatives with selectivities $>99 \%$ at a complete substrate conversion. In addition, the procedure is a true environmentally benign one: DMC is a nontoxic reagent,

† Phone: +39 41 2578687. Fax: +39 41 2578620. E-mail: selva@ unive.it.

(1) Rieu, J. P.; Boucherle, A.; Cousse, H.; Mouzin, G. Tetrahedron 1986, 42, 4095-4131.

(2) Carruthers, W. In Some Modern Methods of Organic Synthesis, 3rd ed.; Cambridge University Press: Cambridge, U.K., 1989.

(3) Brandstrom, A.; J unggren, U. Tetrahedron Lett. 1972, 472.

(4) Abe, F.; Hayashi, T.; Tanaka, M. Chem. Lett. 1990, 5, 765-768.

(5) Tundo, P.; Moraglio, G.; Trotta, F. Ind. Eng. Chem. Res. 1989 28,881 .

(6) Tundo, P.; Trotta, F.; Moraglio, G. J . Chem. Soc., Perkin Trans. 1 1989, 1070

(7) Selva, M.; Marques, C. A.; Tundo, P.J . Chem. Soc., Perkin Trans. 1 1994, 1323-1328.

(8) Bomben, A.; Marques, C. A.; Selva, M.; Tundo, P. Tetrahedron 1995, 51, 11573-11580.

(9) Tundo, P.; Selva, M. Chemtech. 1995, 25 (5), 31-35.

(10) Bomben, A.; Marques, C. A.; Selva, M.; Tundo, P. Red. Trav. Chim. Pays-Bas 1995, 51, 11573-11580.

(11) Bomben, A.; Selva, M.; Tundo, P. J . Chem. Res., (Miniprint) 1997, 2688-2696; J . Chem. Res., Synop. 1997, 448-449.
Chart 1. Nonsteroidal Analgesics<smiles>CC(C)Cc1ccc(C(C)C(=O)OCCCCCCOC(=O)O)cc1</smiles><smiles>COc1ccc2cc(C(C)C(=O)O)ccc2c1</smiles>

Scheme 1

$$
\begin{aligned}
& \mathrm{ArCH}_{2} \mathrm{CN} \stackrel{\mathrm{CH}_{3} \mathrm{X} \text {, Base }}{\longrightarrow} \operatorname{ArCH}\left(\mathrm{CH}_{3}\right) \mathrm{CN}+\operatorname{ArC}\left(\mathrm{CH}_{3}\right)_{2} \mathrm{CN} \\
& \mathrm{X}=\mathrm{Cl}, \mathrm{Br}, \mathrm{I}, \mathrm{OSO}_{3} \mathrm{CH}_{3}
\end{aligned}
$$

the base can be used catalytically, and neither organic nor inorganic byproducts are formed and need to be disposed of. ${ }^{12,13}$

In a further effort to conceive new methods for the selective monoalkylation of arylacetic acid derivatives, we explored the applicability of ortho esters as alkylating agents; the attention was focused on trimethyl orthoformate (TMOF). Although ortho esters are most commonly used for the preparation of ketals and acetals through transacetalation, transetherification, and reduction reactions, ${ }^{14 a, 15-18}$ some successful TM OF-mediated N-methylations of aromatic amines and imidazole-like compounds have also been claimed. ${ }^{19-21}$ More generally, ortho esters have been reported as highly selective O-alkylating agents of primary alcohols in the presence of a montmorillonite catalyst. ${ }^{22}$ Some years ago, we also reported that, at $195^{\circ} \mathrm{C}$ and under basic conditions, TMOF could react with phenol, thiophenol, and phenylacetonitrile to yield the corresponding O-, S-, and C-methylated derivatives; ${ }^{23}$ however, while anisole and thioanisole were obtained by using $\mathrm{K}_{2} \mathrm{CO}_{3}$ as a base, the reaction of phenylacetonitrile proceeded only with t-BuOK and we noticed that a selective mono-C-methylation was elusive.

(12) Selva, M.; Tundo, P. In Green Chemistry: Designing Chemistry for the Environment; Anastas, P., Williamson, T., Eds.; ACS Symposium Series No. 626; American Chemical Society: Washington, DC 1996; Chapter 7, pp 81-91.

(13) Ono, Y. Pure Appl. Chem. 1996, 68, 367-75.

(14) March, J. In Advanced Organic Chemistry, 4th ed.; Wiley \& Sons: New York, 1992: (a) pp 390, 443, 890; (b) pp 378-386.

(15) Branalt, J .; Kvarnstrom, I.; Classon, B.; Samuelsson, B. J . Org. Chem. 1996, 61, 3611-3615.

(16) J ellen, W.; Mittelbach, M.; J unek, H. Monatsh. Chem. 1996, 127, 167-172

(17) Faja, M.; Reese, C. B.; Song, Q. L.; Zhang, P. Z. J . Chem. Soc., Perkin Trans. 1 1997, 191-94.

(18) Inoue, S.; Asami, M.; Honda, K.; Miyazaki, H. Chem. Lett. 1996, $10,889-90$.

(19) Todter, C.; Lackner, H. Synthesis 1997, 5, 567.

(20) Padmanabban, S.; Reddy, N. L.; Durant, G. J . Synth. Commun. 1997, 27, 691-699.

(21) Katritzky, A. R.; Musgrave, R. P.; Rachwal, B.; Zaklika, C. Heterocycles 1995, 41, 345-52.

(22) Sampath Kumar, H. M.; Subba Reddy, B. V.; Mohanty, P. K . Yadav, J. S. Tetrahedron Lett. 1997, 38, 3619-22.

(23) Selva, M.; Trotta, F.; Tundo, P. J . Chem. Soc., Perkin Trans. 2 $1992,519-22$ 
Table 1. Reaction of Phenylacetonitrile with Trimethyl Orthoformate Carried Out in the Presence of t-BuOK and Different Cosolvents ${ }^{\mathrm{a}}$

\begin{tabular}{|c|c|c|c|c|c|c|c|c|}
\hline \multirow[b]{2}{*}{ entry } & \multirow[b]{2}{*}{$\mathrm{T}\left({ }^{\circ} \mathrm{C}\right)$} & \multirow[b]{2}{*}{ cosolvent, $\left(\mathrm{A} / \mathrm{C}_{\mathrm{s}}\right)^{\mathrm{b}}$} & \multirow[b]{2}{*}{ time (min) } & \multirow[b]{2}{*}{ convn, ${ }^{c}(\%)$} & \multicolumn{4}{|c|}{ products (\%) } \\
\hline & & & & & $2 a$ & 3a & $4 a$ & others \\
\hline 1 & 190 & & 60 & 96 & 28 & 11 & 25 & 32 \\
\hline 2 & 140 & & 90 & 85 & 19 & 4 & & 60 \\
\hline 3 & 190 & DMF (4) & 180 & 72 & 36 & 5 & & 31 \\
\hline 4 & 190 & $\mathrm{MeOH}(4)$ & 200 & 98 & 70 & trace $(<1)$ & 28 & \\
\hline 5 & 160 & $\mathrm{MeOH} \mathrm{(4)}$ & 180 & 42 & 4 & & 38 & \\
\hline
\end{tabular}

a All reactions were carried out in an autoclave loaded with a mixture of $\mathrm{PhCH}_{2} \mathrm{CN}(0.5 \mathrm{~g}, 4.3 \mathrm{mmol})$, TMOF (20 mL), and t-BuOK (0.96 $\mathrm{g}, 8.6 \mathrm{mmol})$ in a 1:43:2 molar ratio, respectively. ${ }^{\mathrm{b}} \mathrm{A} / \mathrm{C}_{\mathrm{s}}$ is the volumetric ratio $(\mathrm{mL} / \mathrm{mL})$ between TMOF $(\mathrm{A})$ as the alkylating agent and the cosolvent $\left(\mathrm{C}_{\mathrm{s}}\right)$ (entries 3-5). c\% determined by GC. d $\mathbf{2 a}$, 2-phenylpropionitrile $\left[\mathrm{PhCH}\left(\mathrm{CH}_{3}\right) \mathrm{CN}\right]$; 3a, 2-phenylisobutyronitrile $\left[\mathrm{PhC}\left(\mathrm{CH}_{3}\right)_{2} \mathrm{CN}\right]$; 4a, phenylacetic acid $\left(\mathrm{PhCH}_{2} \mathrm{COOH}\right)$; others, unidentified high-boiling products. \% determined by GC.

We wish to report herethat, in the presence of t-BuOK, TMOF may allow a one-pot transformation of arylacetonitriles into the corresponding 2-aryl proprionitriles with excellent monomethyl selectivities (up to $98-99 \%$ at conversions of $96-98 \%$ ) providing that reactions be performed in the presence of suitable amounts of methanol as a cosolvent.

\section{Results and Discussion}

A first set of experiments was planned by using phenylacetonitrile (1a) as a model compound. As before mentioned, under basic conditions, a high temperature $\left(\geq 190{ }^{\circ} \mathrm{C}\right.$ ) was necessary for TMOF to act as a Cmethylating agent, plausibly through a $\mathrm{B}_{\mathrm{Al}} 2$ mechanism. ${ }^{14 \mathrm{~b}}$ Thus, all the reactions were carried out at $190-210{ }^{\circ} \mathrm{C}$ by loading an autoclave with a mixture of $1 \mathbf{1 a}(0.5 \mathrm{~g} ; 4.3$ $\mathrm{mmol}$ ), TMOF $(20 \mathrm{~mL})$, and t-BuOK (amount: see Table 1). Experiments were performed in the presence of different cosolvents in order to explore whether the medium polarity could have an effect in tuning the selectivity toward the monomethylated product: to this aim, DMF and $\mathrm{MeOH}$ were used. ${ }^{7}$ Each was added separately to the mixture of the reagents in different volumetric ratios with respect to TMOF (see Table 1). This latter reagent was used in a large excess acting both as the methylating agent and the solvent. Table 1 reports the results.

Experiments 1-4 refer to the use of the base in a 2 molar excess with respect to the substrate. When no cosolvents are used, the reaction of $\mathbf{l a}$ with TMOF is rapid though nonselective: at nearly quantitative conversions (85-96\%), mixtures of mono- and dimethylated products $\left[\mathrm{PhCH}\left(\mathrm{CH}_{3}\right) \mathrm{CN}(2 \mathrm{a})\right.$ and $\left.\mathrm{PhC}\left(\mathrm{CH}_{3}\right)_{2} \mathrm{CN}(3 \mathbf{a})\right]$ are al ways observed al ong with $\mathrm{PhCH}_{2} \mathrm{COOH}$ (4a) and other unidentified high-boiling compounds (entries 1 and 2).24

Instead, the use of cosolvents dramatically influences the reaction outcome. At $190^{\circ} \mathrm{C}$, in the presence of DMF (TMOF/DMF $=4$ volume ratio), although the reaction becomes slower ( $72 \%$ conversion after $180 \mathrm{~min})$, the extent of monomethylated products increases: $\mathbf{2 a}$ and $\mathbf{3 a}$ are observed in a 36 and $5 \%$ amounts, respectively, while the sum of other products is 31\% (entry 3 ). A further and marked improvement of the selectivity toward the monomethyl derivative $\mathbf{2} \mathbf{a}$ is achieved by the addition of $\mathrm{MeOH}$ as a cosolvent. Under the same conditions used for DMF $\left(190{ }^{\circ} \mathrm{C}\right.$; TMOF/MeOH $=4$ volume ratio), the presence of $\mathrm{MeOH}$ allows the methylation of $\mathbf{l a}$ to

(24) Unless otherwise indicated, the product \% indicated in Table 1 as well as those of Tables 2 and 3 represents the \% areas of the corresponding gas-chromatographic peaks. However, when authentic samples of compounds $\mathbf{1 a}-\mathbf{4 a}$ were compared to tetradecane as a standard, very similar GC-response factors were observed for them.

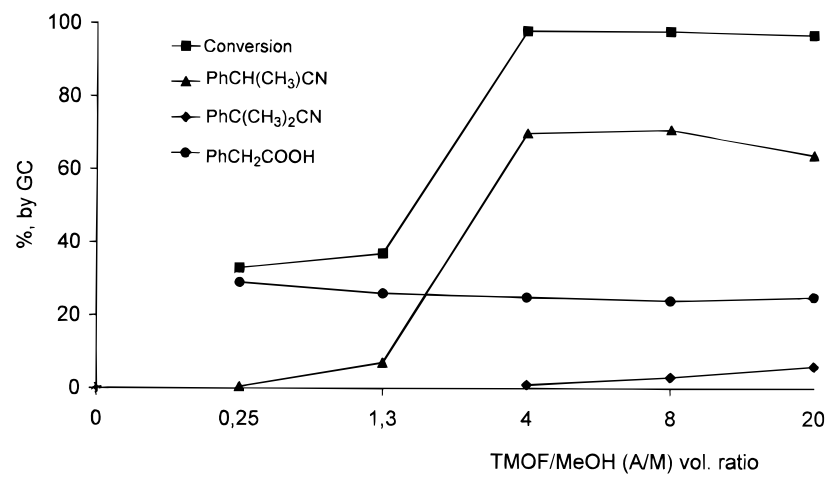

Figure 1. TMOF-mediated methylation of phenylacetonitrile carried out at $190{ }^{\circ} \mathrm{C}$ and in the presence of different amounts of $\mathrm{MeOH}$ as a cosolvent.

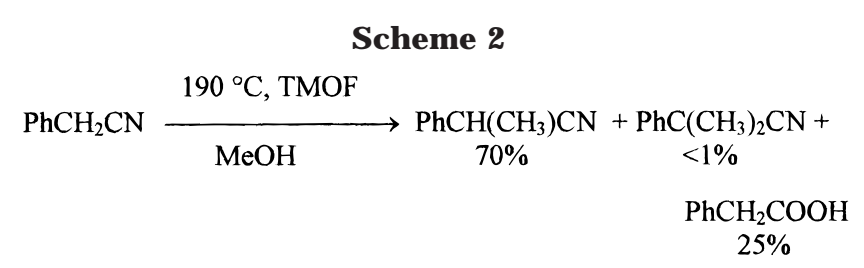

proceed quantitatively (98\% conversion after $200 \mathrm{~min}$ ) yielding $\mathbf{2 a}$ in a $70 \%$ amount, only traces of $\mathbf{3 a}(<1 \%)$, and $\mathbf{4 a}$ as the sole detectable byproduct (25\%) (entry 3 and Scheme 2). At a lower temperature $\left(160^{\circ} \mathrm{C}\right)$, the methylation is markedly slower and $\mathrm{PhCH}_{2} \mathrm{COOH}$ becomes the major product (entry 5).

Under the conditions of entry 4, both the rate and the obtainable monomethyl selectivity appear to be rather independent from the TMOF/substrate ratio. In fact, when this is decreased from 43 (the value of Table 1 ) to 11 (or even to 4.3) by increasing by 4 (or 10) the substrate quantity, no appreciable changes in the reaction time or in the product distribution are observed: after $200 \mathrm{~min}$, conversion is 98 (99) and the $\mathbf{2 a}$, 3a, and $\mathbf{4 a}$ amounts are 69 (70), 2 (2), and $25(25) \%$, respectively.

Encouraged by the promising monomethyl selectivity observed, we began to investigate whether the TMOF mediated methylations could be affected by different amounts of both $\mathrm{MeOH}$ and t-BuOK.

At first, some tests were set up by varying the volume of the added $\mathrm{MeOH}$. Experiments were run at $190{ }^{\circ} \mathrm{C}$ by reacting $\mathrm{PhCH}_{2} \mathrm{CN}$ in the presence of a 2 molar excess of t-BuOK. Figure 1 shows the results for reactions stopped after $180 \mathrm{~min}$. The conversion of the substrate (1a) and the related product distributions are reported versus the TMOF/MeOH (A/M) volumetric ratio; two considerations emerge: (i) Under the explored reaction conditions, a very high mono- to di-methyl selectivity 
Table 2. Monomethylation of Phenylacetonitrile with Trimethyl Orthoformate in the Presence of Different Amounts of Methanol and t-BuOKa

\begin{tabular}{|c|c|c|c|c|c|c|c|c|}
\hline \multirow[b]{2}{*}{ entry } & \multirow{2}{*}{$\begin{array}{c}\mathrm{T} \\
\left({ }^{\circ} \mathrm{C}\right)\end{array}$} & \multirow{2}{*}{$\begin{array}{c}\mathrm{B} / \mathrm{S}^{\mathrm{b}} \\
\text { (mol ratio) }\end{array}$} & \multirow{2}{*}{$\begin{array}{c}\mathrm{A} / \mathrm{M}^{\mathrm{c}} \\
\text { (vol ratio) }\end{array}$} & \multirow{2}{*}{$\begin{array}{l}\text { time } \\
\text { (min) }\end{array}$} & \multirow{2}{*}{$\begin{array}{c}\text { Convn }{ }^{d} \\
(\%)\end{array}$} & \multicolumn{3}{|c|}{ products (\%) } \\
\hline & & & & & & $\overline{2 a}$ & $3 a$ & $\mathbf{4 a}$ \\
\hline \multirow[t]{2}{*}{1} & 190 & 1 & 4 & 180 & 43 & 41 & & \\
\hline & & & & 420 & 55 & 53 & $<0.5$ & \\
\hline 2 & 210 & 1 & 4 & 465 & 67 & 66 & 0.6 & \\
\hline \multirow[t]{2}{*}{3} & 210 & 1.2 & 4 & 435 & 62 & 60 & 0.6 & \\
\hline & & & & 840 & 84 & 80 & 1 & \\
\hline 4 & 200 & 1.5 & 4 & 300 & 96 & 92 & 1 & \\
\hline 5 & 210 & 1.5 & 8 & 570 & 85 & 82 & 2 & \\
\hline 6 & 210 & 1.2 & 20 & 470 & 91 & 81 & 8 & \\
\hline 7 & 190 & 1.2 & 8 & 300 & 95 & 88 & 4 & \\
\hline 8 & 190 & 1.2 & 20 & 300 & 93 & 82 & 9 & \\
\hline 9 & 210 & 0.5 & 8 & 950 & 40 & 37 & $<0.5$ & \\
\hline
\end{tabular}

a All reactions were carried out in an autoclave loaded with $\mathrm{PhCH}_{2} \mathrm{CN}$ (0.5 g; $4.2 \mathrm{mmol}$ ) and TMOF (20 mL); $\mathrm{MeOH}$ as a cosolvent and t-BuOK were added as reported in the footnotes $b$ and $c .{ }^{b} B / S$ is the molar ratio between the base (B) and the substrate (S). ${ }^{c} \mathrm{~A} / \mathrm{M}$ is the volumetric ratio between TMOF (A) as the alkylating agent and methanol (M) as the cosolvent. $d \%$ determined by GC. ${ }^{\mathrm{e}} \mathbf{2} \mathbf{a}, \mathbf{3} \mathbf{a}$, and $\mathbf{4 a}$ are defined as in Table 1; \% determined by GC.

$\left(\mathrm{S}_{M / D}=96-99 \%\right)^{25}$ is always attained. However, an optimal $A / M$ of 4 may be identified whereby $S_{M / D}$ reaches a maximum of $99 \%$. (ii) Although experiments are performed under a $\mathrm{N}_{2}$ atmosphere, the formation of $\mathrm{PhCH}_{2} \mathrm{COOH}$ appears unavoi dable and quite constant throughout all the examined reactions: $\mathbf{4 a}$ is observed in a $25-30 \%$ amount regardless of the added methanol.

Under the conditions we found for the highest $\mathrm{S}_{M / D}$ $(A / M=4)$, we then explored whether any base effects could be observable; $\mathrm{PhCH}_{2} \mathrm{CN}$ was reacted with TMOF by varying the t-BuOK amount over the range of 0.51.5 molar equiv with respect to 1 a. Table 2 reports the results.

The decrease of the quantity of t-BuOK drastically depresses the reaction rate. At $190{ }^{\circ} \mathrm{C}$ and $\mathrm{B} / \mathrm{S}$ (base/ substrate molar ratio) of 1, low conversions (43-55\%) are observed even for a prolonged reaction time [compare entry 4 of Table $1(B / S=2)$ to entry 1 of Table 2]. More generally, when $\mathrm{B} / \mathrm{S} \leq 1.5$, a higher reaction temperature becomes necessary to push the methylation at an appreciable rate (entries $2-4$ ). Thus, at a $B / S$ of 1.5 , a distinct improvement is observed at $200{ }^{\circ} \mathrm{C}$ : after 300 $\min$, the reaction goes to a substantial completion $(96 \%$ conversion: entry 4).

Despite the higher temperature $\left(210\right.$ vs $\left.190{ }^{\circ} \mathrm{C}\right)$ and longer reaction times (300-850 min vs $180 \mathrm{~min}$ ), all the tested reactions proceed with a very high monomethyl selectivity $\left(\mathrm{S}_{M / D} \geq 99 \%\right)$. In addition, the formation of $\mathrm{PhCH}_{2} \mathrm{COOH}$ is observed in only trace amounts $(\leq 2 \%)$. $\mathrm{A} \mathrm{B} / \mathrm{S}$ of 1.5 appears to be the best compromise between the monomethylation rate and the byproducts minimizati on: after $300 \mathrm{~min}$, a conversion of $96 \%$ is reached with $\mathbf{2 a}$, 3a, and $\mathbf{4 a}$ formed in 92, 1, and $1 \%$ amounts, respectively (entry 4).

As far as the formation of $\mathbf{4 a}$ is concerned, this has to be ascribed to a side reaction of hydrolysis of $\mathrm{PhCH}_{2} \mathrm{CN}$ taking place concurrently with respect to the methylation process. This behavior is likely to be due to some water (coming from the reagents) whose availability for the hydrolysis is very sensitive to the quantity of t-BuOK;

(25) Mono- to dimethyl selectivity $\left(\mathrm{S}_{\mathrm{M} / \mathrm{D}}\right)$ is calculated as: $\{\%$ of $\mathrm{PhCH}\left(\mathrm{CH}_{3}\right) \mathrm{CN} /\left[\%\right.$ of $\mathrm{PhCH}\left(\mathrm{CH}_{3}\right) \mathrm{CN}+\%$ of $\left.\left.\mathrm{PhC}\left(\mathrm{CH}_{3}\right)_{2} \mathrm{CN}\right]\right\} \times 100$ where \% is defined in ref 24 . in fact, such a reaction becomes important only when the base is in a 2-fold excess with respect to 1 a $(B / S=2$, Table 1 and Figure 1).

The data of Figure 1 and of entries 1-4 of Table 2 allow one to get a measure of the importance of both the cosolvent $\mathrm{MeOH}$ and the base. While the former $(\mathrm{MeOH})$ deeply influences the methylation selectivity, the latter (t-BuOK) mainly affects the reaction rate and the extent of the nitrile hydrolysis. As a further support to this, Table 2 reports the outcomes of the reaction of $\mathbf{l a}$ with TMOF carried out by using A/M ratios of 8 and of 20 and $\mathrm{B} / \mathrm{S}$ of $0.5,1.2$, and 1.5 (entries $5-9$ ). These results shows the following: (i) At every given $\mathrm{B} / \mathrm{S}$ ratio, the decrease of the added methanol produces a drop in the monomethyl selectivity (compare entries 4, 7, and 8) and, concurrently, an increased methylation rate (compare entries 3, 5, and 6); accordingly, the reduction of the cosolvent also al lows the methylation to occur at a lower temperature ( 190 vs $210^{\circ} \mathrm{C}$; compare entries 4 and $8-9$ ). (ii) At every given $\mathrm{A} / \mathrm{M}$ ratio, the increase of the base amount results in a marked increase of the reaction rate as well, while selectivity is scarcely, if at all, affected (compare entries 3 and 4, 5 and 7, and 6 and 8). Finally, at a $\mathrm{S} / \mathrm{B}$ ratio of 0.5 , the reaction is extremely slow even by using small volumes of $\mathrm{MeOH}$ (entry 9 ).

Sodi um methoxide was also used as a base. However, under the conditions of entry 4 , Table $2\left(200^{\circ} \mathrm{C}\right.$; B/S = 1.5; $A / M=4)$, the reaction of phenylacetonitrile with TMOF was not as satisfactory as in the case of t-BuOK: after $360 \mathrm{~min}$, the conversion was $75 \%$ and $\mathbf{2 a}$ and $\mathbf{4 a}$ were observed in 65 and $2 \%$ amounts, respectively, the remainder (8\%) being unidentified byproducts.

To investigate the synthetic applicability of the explored methylation procedure, both phenylacetonitrile and different arylacetonitriles [Ar: $4-\mathrm{CH}_{3} \mathrm{OC}_{6} \mathrm{H}_{4}$ (1) 2- $\mathrm{CH}_{3} \mathrm{OC}_{6} \mathrm{H}_{4}(\mathbf{l c}), 4-\mathrm{CH}_{3} \mathrm{C}_{6} \mathrm{H}_{4}$ (1d), 4- $\mathrm{ClC}_{6} \mathrm{H}_{4}$ (1e), and naphthyl (1f)] were reacted with TMOF in the presence of $\mathrm{MeOH}$ and $\mathrm{t}-\mathrm{BuOK}$. Table 3 reports the results.

Data for la refer to a reaction carried out under the conditions of entry 4 in Table $2\left(\mathrm{~A} / \mathrm{M}=4,200^{\circ} \mathrm{C}, \mathrm{B} / \mathrm{S}=\right.$ 1.5) except for the substrate amount which is 10 times larger ( $5 \mathrm{~g}$ instead of $0.5 \mathrm{~g}$ ); the quantity of the base is al so proportionally increased.

As far as the other nitriles are concerned, Table 3 shows that the reaction conditions need to be tuned according to the reactants' structure. Electron-donating substituents of weak and medium strength $\left(4-\mathrm{CH}_{3}-\right.$, 4- $\mathrm{CH}_{3} \mathrm{O}-$, and $2-\mathrm{CH}_{3} \mathrm{O}-$ ) produce a decrease of the reaction rate with respect to phenylacetonitrile (compare entries $1,2-3,7$, and 9). The effect is much more evident for $\mathbf{~ I c ~}\left(2 \mathrm{CH}_{3} \mathrm{OC}_{6} \mathrm{H}_{4} \mathrm{CH}_{2} \mathrm{CN}\right)$ because also a relevant steric hindrance operates at the ortho position (entries 7 and 8). Therefore, reactions have to be run at $210{ }^{\circ} \mathrm{C}$ by increasing the base amount at $\mathrm{B} / \mathrm{S}$ of 3 (compounds $\mathbf{l b}, \mathbf{c}$ ) and of 2 (1d). Despite that, no hydrolysis of the substrate to the respective arylacetic acid is observed. However, although no dimethylation occurs, unidentified byproducts form (2-25\%; entries 5-10).

The methylation of compounds $1 e\left(4-\mathrm{ClC}_{6} \mathrm{H}_{4} \mathrm{CH}_{2} \mathrm{CN}\right)$ and $\mathbf{I f}\left(\mathrm{C}_{10} \mathrm{H}_{8} \mathrm{CH}_{2} \mathrm{CN}\right)$ with TMOF may proceed under the same conditions used for $1 \mathrm{a}\left(200^{\circ} \mathrm{C}, \mathrm{B} / \mathrm{S}=1.5\right.$, and $\mathrm{A} / \mathrm{M}$ $=4$ ) with a $S_{M / D}$ of $97 \%$ in both cases (entries 12 and $13)$, though byproducts are observed for 1 e $(17-18 \%$; entries 11-12). Some dimethylation (19\%) takes place for $\mathbf{1 f}$ only at a very high conversion (96\%; entry 14). 
Table 3. Mono-C-Methylation of Different Arylacetonitriles with Trimethyl Orthoformate in the Presence of MeOH and t-BuOKa

\begin{tabular}{|c|c|c|c|c|c|c|c|c|c|c|}
\hline \multirow[b]{2}{*}{ entry } & \multirow[b]{2}{*}{$\mathrm{ArCH}_{2} \mathrm{CN}(\mathrm{g})$} & \multirow{2}{*}{$\begin{array}{c}\mathrm{T} \\
\left({ }^{\circ} \mathrm{C}\right)\end{array}$} & \multirow{2}{*}{$\begin{array}{c}\mathrm{B} / \mathrm{S}^{\mathrm{b}} \\
\text { (molar ratio) }\end{array}$} & \multirow{2}{*}{$\begin{array}{c}\mathrm{A} / \mathrm{M}, \mathrm{b} \\
\text { (vol ratio) }\end{array}$} & \multirow{2}{*}{$\begin{array}{l}\text { time } \\
(\min )\end{array}$} & \multirow{2}{*}{$\begin{array}{c}\text { convnc } \\
(\%)\end{array}$} & \multicolumn{2}{|c|}{ products (\%)d } & \multirow[b]{2}{*}{ others } & \multirow{2}{*}{$\begin{array}{c}\text { yield } \\
(\%)\end{array}$} \\
\hline & & & & & & & $\mathbf{M}$ & D & & \\
\hline 1 & la, $\mathrm{Ar}=\mathrm{Ph}(5)$ & 200 & 1.5 & 4 & 300 & 96 & 93 & 1 & & 49 \\
\hline 2 & $\mathbf{l b}, \mathrm{Ar}=4-\mathrm{CH}_{3} \mathrm{OC}_{6} \mathrm{H}_{4}(0.5)$ & 190 & 1.5 & 4 & 300 & 31 & 31 & & & \\
\hline 3 & & 200 & 1.5 & 4 & 840 & 48 & 48 & & & \\
\hline 4 & & 210 & 1.8 & 8 & 810 & 50 & 50 & & & \\
\hline 5 & & 210 & 2.5 & 8 & 570 & 72 & 70 & & 2 & \\
\hline 6 & & 210 & 3 & 8 & 850 & 94 & 87 & 5 & 2 & 37 \\
\hline 7 & $\mathbf{1 c}, \mathrm{Ar}=2-\mathrm{CH}_{3} \mathrm{OC}_{6} \mathrm{H}_{4}(0.5)$ & 210 & 1.5 & 4 & 420 & 24 & 19 & & 5 & \\
\hline 8 & & 210 & 3 & 4 & 960 & 72 & 47 & & 25 & \\
\hline 9 & $\mathbf{1 d}, \mathrm{Ar}=4-\mathrm{CH}_{3} \mathrm{C}_{6} \mathrm{H}_{4}(0.5)$ & 200 & 1.5 & 4 & 360 & 79 & 76 & & 3 & \\
\hline 10 & & 200 & 2 & 4 & 270 & 96 & 82 & & 14 & 60 \\
\hline 11 & 1e, $\mathrm{Ar}=4-\mathrm{ClC}_{6} \mathrm{H}_{4}(0.5)$ & 200 & 1.5 & 4 & 200 & 78 & 61 & & 17 & \\
\hline 12 & & 200 & 1.5 & 4 & 300 & 93 & 73 & 2 & 18 & 39 \\
\hline 13 & $\mathbf{1 f}, \mathrm{Ar}=\mathrm{C}_{10} \mathrm{H}_{8}(0.5)$ & 200 & 1.5 & 4 & 300 & 84 & 82 & 2 & & 47 \\
\hline 14 & & 200 & 1.5 & 2.5 & 380 & 96 & 77 & 19 & & \\
\hline
\end{tabular}

a All reactions were carried out in an autoclave loaded with the substrate, TMOF $(20 \mathrm{~mL})$, and t-BuOK in the reported molar ratio. $\mathrm{b} B / \mathrm{S}$ and $\mathrm{A} / \mathrm{M}$ are the molar and volumetric ratio as defined in footnotes $\mathrm{b}$ and $\mathrm{c}$ of Table $2 . \mathrm{c} \%$ determined by GC.d $\%$ determined by GC; $\mathrm{M}$ and $\mathrm{D}$, monomethylated $\left[\mathrm{ArCH}\left(\mathrm{CH}_{3}\right) \mathrm{CN}\right.$ ] and dimethylated $\left[\mathrm{ArC}\left(\mathrm{CH}_{3}\right)_{2} \mathrm{CN}\right.$ ] derivatives, respectively; others, unidentified high boiling products. e I solated yields.

These results suggest that the reaction conditions for the methylation of different arylacetonitriles with TMOF need to be optimized case-by-case to avoid (or minimize) the byproduct formation.

The isolated yields of products 2 appear to be moderate (37-60\%): these values correspond to the $50-70 \%$ of the gas-chromatographic percent of the monomethyl derivatives $(\mathbf{M})$ reported in Table $3 .{ }^{24}$ Although yields have not been optimized, this result can be also partly ascribed to some decomposition of the starting reagents. This has been observed, for instance, after the distillation of $\mathbf{2 a}$ : a residual tar is recovered as a nondistillable and nonanalyzable (by GC) material.

\section{Conclusions}

The here described procedure proposes a new one-pot transformation of arylacetonitriles into 2-arylpropionitriles ( $\mathbf{2} \mathbf{a}-\mathbf{f})$ by using trimethyl orthoformate as the alkylating agent. The reaction occurs with a high monomethyl selectivity (up to 99\%) at complete substrate conversions. Although this preliminary investigation is far from explaining the mechanism responsible for such an intriguing result, it has revealed that the reaction outcome is mostly dependent upon the presence of methanol as a cosolvent. In fact, it is this alcohol that tunes the reaction toward a very selective monomethylation process.

On the other hand, the base used (t-BuOK) has major effects on the reaction rate.

Finally, the procedure may also have an environmental significance; in fact, TMOF is by far a less toxic alternative to current methylating agents (e.g. methyl halides or dimethyl sulfate).

\section{Experimental Section}

All the compounds used were ACS grade and were employed without further purification. ${ }^{1 H} \mathrm{NMR}$ spectra were recorded at $400 \mathrm{MHz}$ using $\mathrm{CDCl}_{3}$ as the solvent. $\mathrm{GC}$ analyses were performed using a $30 \mathrm{~m}$, DB5 capillary column. GC/MS analyses were performed by a mass detector at $70 \mathrm{eV}$ coupled to a gas chromatograph fitted with a $30 \mathrm{~m}$, DB5 capillary column. Melting points are uncorrected.

Reactions Carried Out in Autoclave. General Procedure. All methylation reactions by TMOF were carried out in a stainless steel (AISI 316) autodave (internal volume of 250
$\mathrm{mL}$ ), equipped with a purging valve, through which, at room temperature, air was removed before each reaction by purging with $\mathrm{N}_{2}$ stream. A magnetically stirred mixture of the alkylating agent, the arylacetonitrile, the base (t-BuOK), and methanol (where indicated) in the reported molar and volumetric ratios (see Tables 1-3) was heated in the autoclave, itself heated in an el ectrical oven, at the desired temperature $\left(190-210^{\circ} \mathrm{C}\right)$. The corresponding internal pressure was of 8-12 bar. A thermocouple (T) and a needle valve $(\mathrm{V})$ were fixed onto the autoclave head: while the former ( $T$ ) (dipping into the reaction mixture) allowed a constant check of the reaction temperature, the latter (V) was connected to a $1 / 8$ in. stainless steel sampling pipe immersed into the reaction mixture. In this way, the internal pressure allowed samples to be withdrawn through $\mathrm{V}$ at intervals, during the course of the reaction. Before GC analyses, each sample $(0.2-0.3 \mathrm{~mL})$ was cooled to room temperature, added to diethyl ether $(2 \mathrm{~mL})$, water $(2 \mathrm{~mL})$, and diluted $\mathrm{HCl}$ (3 drops), and finally shaken. ${ }^{26}$ The organic layer was then analyzed by GC.

Typical Experimental Procedure. Monomethylation of Phenylacetonitrile (Entry 4, Table 2). The above-described autoclave was loaded with a solution of phenylacetonitrile $(0.5$ $\mathrm{g}, 4.3 \mathrm{mmol})$, trimethyl orthoformate $(20 \mathrm{~mL}, 0.18 \mathrm{~mol})$, and methanol $(5 \mathrm{~mL}, 0.12 \mathrm{~mol})$. To this solution, t-BuOK $(0.72 \mathrm{~g}$, $6.4 \mathrm{mmol}$ ) was added. The autoclave was then closed, purged with a $\mathrm{N}_{2}$ stream, and finally heated in an electrical oven at $200{ }^{\circ} \mathrm{C}$, while the reaction mixture was kept under a magnetic stirring. At intervals (30 min), samples were withdrawn and analyzed by GC: a substantially quantitative conversion of the substrate was observed after $300 \mathrm{~min}$.

Purification of Products. After the reaction was completed, the autoclave was rapidly cooled to room temperature in a water bath. Then, the reaction mixture was transferred into a separatory funnel, added to water $(50 \mathrm{~mL})$, and carefully acidified with diluted $\mathrm{HCl}(10 \%)$ until a $\mathrm{pH}$ of $4-5$ was reached (checked by a pH paper). The organic phase was then extracted with diethyl ether $(3 \times 50 \mathrm{~mL})$ and the combined layers dried over sodium sulfate and filtered. The light solvents (TMOF and diethyl ether) were removed by rotary evaporation, and the residue was distilled under vacuum (in the case of compound 2a) or purified by gravity column chromatography for the monomethylated derivatives $\mathbf{2 b}, \mathbf{d}-\mathbf{f}$ (silica gel, Merck F60; eluting solvent, diethyl ether/petroleum ether in a 30:70 v/v ratio). The vacuum distillation was performed in a microClaisen distillation apparatus with a fused-on Liebig condenser.

(26) The addition of $\mathrm{HCl}$ transforms anions such as $\mathrm{ArCH}^{-} \mathrm{CN}$, $\mathrm{ArC}^{-}\left(\mathrm{CH}_{3}\right) \mathrm{CN}$, etc., into the corresponding conjugated acids $\left(\mathrm{PhCH}_{2}-\right.$ $\mathrm{CN}$, ...) that can be so analyzed by GC. This hydrolytic workup does not certainly hydrolyze the reacting nitrile 1 . If so, also $\operatorname{ArCH}\left(\mathrm{CH}_{3}\right)^{-}$ $\mathrm{COOH}$ (coming from the hydrolysis of 2) should be observed, but we never detected it. 
Compounds $\mathbf{2 a , b , d , e ~ w e r e ~ c o m p a r e d ~ t o ~ a u t h e n t i c ~ s a m p l e s ~}$ whose full analytical data were previously reported by us; ${ }^{4}$ data for $\mathbf{2 f}$ agreed with the reported ones. ${ }^{27} \mathbf{2 c}$ was not isolated; its characterization was through GC/MS analysis by comparison to an authentic sample. ${ }^{4}$

(27) Freerksen, R. W.; Selikson, S. J .; Wroble, R. R. J . Org. Chem. 1983, 48, 4087-96.
Acknowledgment. This work was supported by Inca (Interuniversity Consortium "The Chemistry for the Environment") and MURST (Ministero Università e Ricerca Scientifica Tecnologica).

J $0980914 S$ 